\title{
A COLÔNIA AGRÍCOLA NACIONAL DE GOIÁS E A REDEFINIÇÃO NOS USOS DO TERRITÓRIO
}

\author{
The National Agricultural Colony of Goiás and the redefinition in the \\ uses of territory
}

\author{
Wagner Abadio de Freitas \\ Instituto Federal Goiano, Ceres, Goiás, Brasil \\ wagner.freitas@ifgoiano.edu.br
}

Marcelo de Mello

Universidade Estadual de Goiás, Cidade de Goiás, Goiás, Brasil

ueg.marcelo@gmail.com

Artigo recebido em 26/02/2014 e aceito para publicação em 31/07/2014

RESUMO: O discurso da Marcha para o Oeste produzido pelo Estado Novo foi materializado com ações efetivas. O povoamento do interior do país e a criação de uma infraestrutura mínima foram fundamentais para a penetração do capital e a redefinição de seu território. Nesta perspectiva, investigou-se o processo de criação das Colônias Agrícolas Nacionais, suas dinâmicas regionais, os avanços técnicos e os resultados produzidos pelas mesmas. O destaque principal foi direcionado à Colônia Agrícola Nacional de Goiás, tendo em vista a concepção do processo de ocupação e produção do território goiano, pautado em questões naturais da região "O Mato Grosso de Goiás", bem como na inserção dos sistemas de engenharia (infraestrutura) que possibilitaram diferentes usos do território, cuja materialidade definiu a forma e o conteúdo do espaço produzido a partir da constituição de um meio técnico. O presente trabalho foi estruturado a partir da análise de decretos e referenciais teóricos pertinentes ao tema, com vistas à pavimentação de um caminho que contribua com o entendimento do processo investigado.

Palavras chave: Povoamento; Colônias Agrícolas; Produção do território; Meio técnico.

\begin{abstract}
The speech of March to the West produced by the New State was materialized with effective actions. The settlement, the occupation of the interior of the country and the creation of a minimal infrastructure were not only necessary but fundamental for the penetration of the capital and the production in the territory. This perspective, this research tried to understand the process of creation of the National Agricultural Colonies, their regional dynamics, the technical advances and the results produced by them. The emphasis was associated with the National Agricultural Colony of Goiás, considering the design of the occupation of Goiano territory and the production process, based on natural issues in the region "Mato Grosso de Goiás" and the insertion on engineering systems (infrastructure) that allowed different uses, whose materiality defined the form and content of the space produced from technical means. This work was structured based on the analysis of decrees and theoretical frameworks relevant to the topic, in order to establish a way that can contribute to understand the investigated process.
\end{abstract}

Keywords: Settlement. Agricultural colonies; Production planning; Technical means. 


\section{INTRODUÇÃO}

A incorporação de "novos" territórios à dinâmica capitalista sediada na Região Concentrada, definida por Santos e Silveira (2004) como um espaço fluído devido ao deslocamento dos fatores de produção sem perda da eficiência produtiva, objetivou integrar o território brasileiro. Para Waibel (1958), o Estado de Goiás foi incorporado a esta dinâmica, pois estava destinado a desempenhar papel relevante na chamada Marcha para o Oeste, pensada para redefinir a lógica produtiva em escala nacional.

O território brasileiro foi envolvido por um movimento que, paulatinamente, buscou atender às novas demandas de um sistema produtivo em processo de modernização. Portanto, as relações de poder constituídas foram reestruturadas por agentes políticos e econômicos inseridos na gestão desta dinâmica.

Novas disciplinas alteraram as relações travadas entre o homem, o tempo e o espaço (MELLO, 2009), proporcionando práticas inovadoras que, direta ou indiretamente, iniciaram a composição dos enredos e das tramas responsáveis pela produção das rugosidades presentes, atualmente, no território nacional.

Em um momento anterior às redefinições aqui mencionadas, o meio natural era utilizado pelo homem para garantir sua sobrevivência. A natureza era vista como objeto a ser apropriado e transformado para atender às demandas elementares das comunidades, conformando o que Claval (1979) chamou de geometria das formas elementares do poder, produzida pelas relações econômicas e pelo jogo das forças ideológicas de seu tempo. Para Santos (2006), nesse período, as motivações de uso do território eram, sobretudo, locais, sendo o intercâmbio percebido de maneira tímida.

Com a emergência de um espaço progressivamente tecnificado, ocorreu a transição de um meio natural para um meio técnico, proporcionando uma sobreposição entre os tempos naturais e os humanizados. A implantação de objetos técnicos no território promoveu uma superação gradativa das limitações impostas pelo meio natural, alterando as referências temporais e espaciais vigentes nos processos produtivos.

As transformações ocorridas a partir das décadas de 1930 e 1940, no Brasil, abriram as portas para um processo de interiorização do território nacional com forte teor político: ocupar os espaços "vazios" do oeste era uma forma de garantir a presença e a autoridade dos agentes oficiais. O Estado, por meio do Departamento de Imprensa e Propaganda (DIP), difundiu o discurso da Marcha para o Oeste, até sua materialização por meio das Colônias Agrícolas Nacionais (CAN).

Contudo, este movimento não foi marcado por uma recepção harmônica por parte de todos os que por ele foram afetados. Os estudos realizados por Monbeig (1998) contextualizaram as tensas relações travadas entre pioneiros e fazendeiros. Os embates retratados pelo geógrafo francês narram a conquista do oeste brasileiro: à medida que as lavouras de café avançavam para o oeste, o espaço natural era artificializado e as estruturas de poder alteradas. Pesquisas como as de Monbeig (Idem) contribuem para o entendimento do avanço da fronteira em direção ao interior do país.

A "Marcha Pioneira" ou a "Franja Pioneira", analisada por Monbeig, foi percebida como instável e incerta, com significados e intenções carregados de subjetividades; mas, simultaneamente, centrada em um objetivo definido e pautada em uma disciplina territorializadora. Para Waibel (1958), as faixas pioneiras estão, normalmente, situadas nas franjas da civilização e na periferia das áreas habitadas. Elas separam a "selva desabitada" do interior, das partes povoadas localizadas na faixa litorânea.

Para regular as relações territorializadoras e atender aos interesses dos agentes políticos e econômicos responsáveis por tais transformações, o Decreto Federal $\mathrm{n}^{\circ} 2.009$, de 9 de fevereiro de 1940 foi fundamental. Nele, foram estabelecidos os critérios para o encaminhamento de trabalhadores rurais e urbanos para locais considerados promissores. Estava em curso um processo de incorporação de regiões "não civilizadas", localizadas no interior país, com o objetivo de inseri-las nas atividades organizadas para a reprodução ampliada do capital sediado na Região Concentrada. Tal processo pautou-se em uma ocupação especulativa de terras e cumpriu um papel decisivo (REYDON, 2007, p. 250) no preenchimento dos espaços vazios localizados no território nacional.

O presente artigo aborda parte desta dinâmica modernizadora a partir da criação das Colônias Agrícolas Nacionais (CAN). Como cenário privilegiado tem-se o Estado de Goiás, pois o mesmo foi contemplado com a 
criação da primeira Colônia: a Colônia Agrícola Nacional de Goiás (CANG). Os esforços empreendidos buscaram o entendimento do processo de redefinição dos usos do território, por meio da implementação da Marcha para o Oeste, durante o governo de Getúlio Vargas; bem como das transformações ocorridas na região do "Mato Grosso de Goiás", através da inserção de objetos técnicos.

No curso da investigação, os registros das alterações dos usos de um território caracterizado pela penetração de um processo modernizador, com vistas ao atendimento das demandas de agentes políticos e econômicos representados por um Estado autoritário e centralizador, foram pautados em pesquisas bibliográficas, documentais e de campo. Recentemente, investigações como a de Cardoso (2005), Silva (2008) e Castilho (2009), se dedicaram a desvelar o processo de integração do interior do país ao sistema produtivo hegemonicamente situado na Região Concentrada. O presente artigo se apresenta como mais uma contribuição para a compreensão de um intrincado processo, que ocupa um lugar de destaque na obra de Geógrafos como Monbeig (1998) e Waibel (1958). É o que será apresentado a seguir.

\section{O ESTADO E O TERRITÓRIO: DO DISCURSO À MATERIALIZAÇÃO}

Elaborar uma estratégia de ocupação de um território como o brasileiro, com uma área de 8.515.767,049 $\mathrm{km}^{2}$, é uma tarefa de grande magnitude. Esta ação exigiu esforço para o atendimento de interesses políticos e econômicos. Os anseios relacionados à ocupação territorial fizeram parte de um debate nacional. A conquista dos objetivos propostos se deu por meio da materialização de objetos técnicos inseridos no território, com vistas à implementação de processos de modernização produtiva.

Segundo Santos e Silveira (2004), esse período está situado entre o início do século XX e a década de 1940. Naquele momento, a unidade territorial brasileira foi reconfigurada e as relações territorializadoras ampliadas a partir do incremento de objetos técnicos.

As características do meio natural definiram os locais para a instalação das Colônias Agrícolas. Alguns elementos eram considerados fundamentais na escolha do local: cursos permanentes d'água para o abastecimento, se possível com quedas d'água, solos propícios para a atividade agrícola, situação climática condizente com as culturas regionais e a existência de vegetação densa, que, naquela ocasião, foi classificada por Waibel (1958) como "Mata de primeira classe" ou como floresta semi-decídua.

O Estado de Goiás, assim como outros Estados da federação localizados no interior do país, era percebido como muito distante. Sua relação com a Região Concentrada era limitada pelas restrições do meio natural. Com os avanços técnicos foram intensificados os fluxos de pessoas, serviços e mercadorias entre Goiás e a Região Concentrada.

É importante ressaltar que no início da década de 1930 foi anunciada e iniciada a construção de uma nova capital para o Estado de Goiás: Goiânia. Certamente, as demandas estaduais estavam em consonância com as nacionais, já que vigorava um regime político autoritário, no qual o chefe do poder executivo federal nomeou o chefe do executivo goiano.

Para articular as ações oficiais em suas diversas escalas, o Decreto Federal $n^{\circ} 3.059$, de 14 de fevereiro de 1941, determinou que

Além dos núcleos coloniais a que se refere o decreto-lei $n^{\circ} 2.009$, de 9 defevereiro de 1940, o Governo Federal, em colaboração com os Governos estaduais e municipais e todos os órgãos da administração pública federal $e$ por intermédio do Ministério da Agricultu$r a$, promoverá a fundação e instalação de grandes Colônias Agrícolas Nacionais, as quais serão destinadas a receber e fixar, como proprietários rurais, cidadãos brasileiros reconhecidamente pobres que revelem aptidão para os trabalhos agrícolas e, excepcionalmente, agricultores qualificados estrangeiros. (BRASIL, 1941).

À medida que o governo expedia Decretos criando as CAN, novas relações locais e regionais eram estabelecidas, com vistas à ampliação do controle territorial centrado nas aspirações de Getúlio Vargas. O Estado preocupava-se em legitimar sua presença nas Unidades da Federação. As Figuras 01 e 02 destacam as oito Colônias instituídas após a publicação do Decreto Federal no 3.059 . 
Figura 01: Ordem cronológica das oito Colônias Agrícolas criadas pelo Governo Federal.

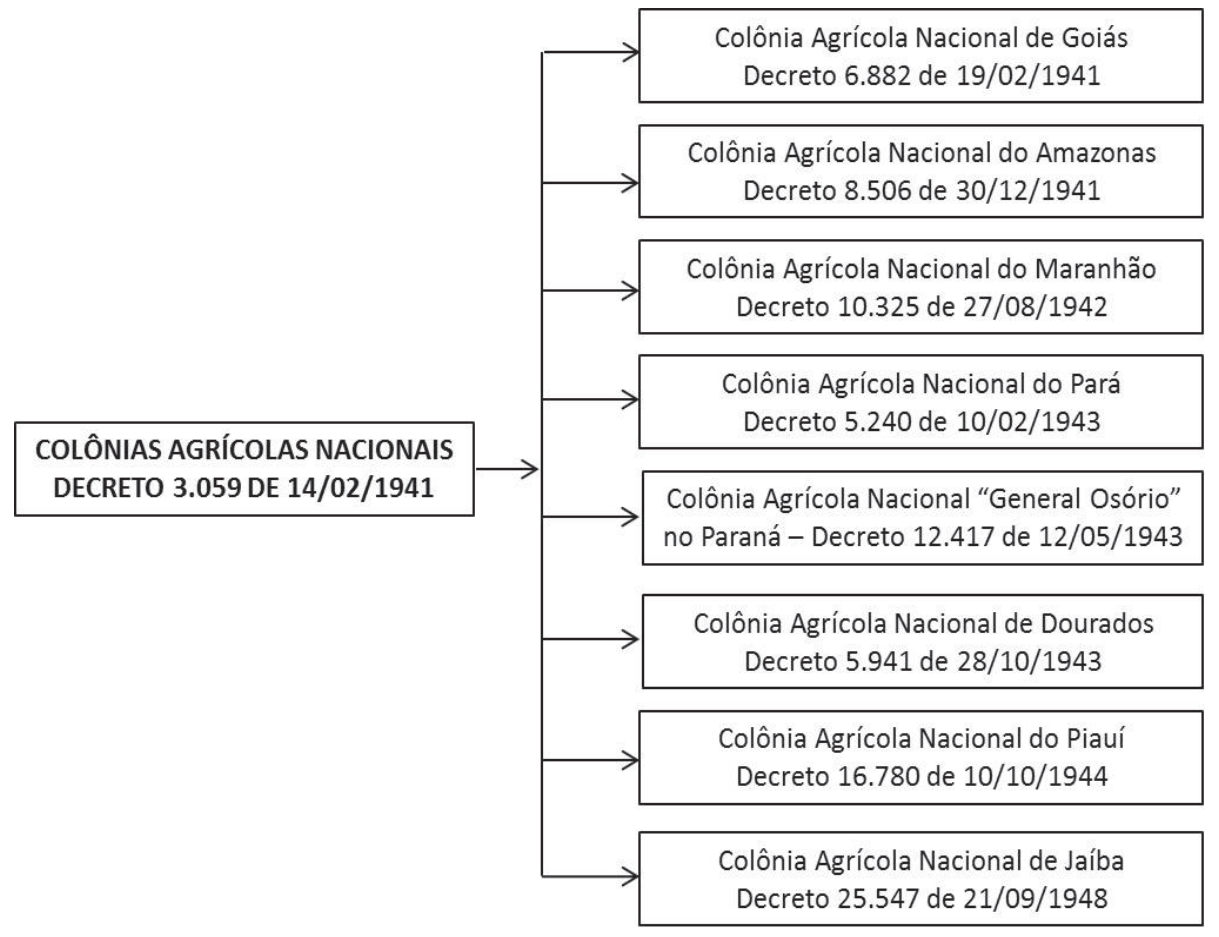

Organizado pelos autores

Figura 02: Território nacional e a localização das oito Colônias Agrícolas Nacionais.

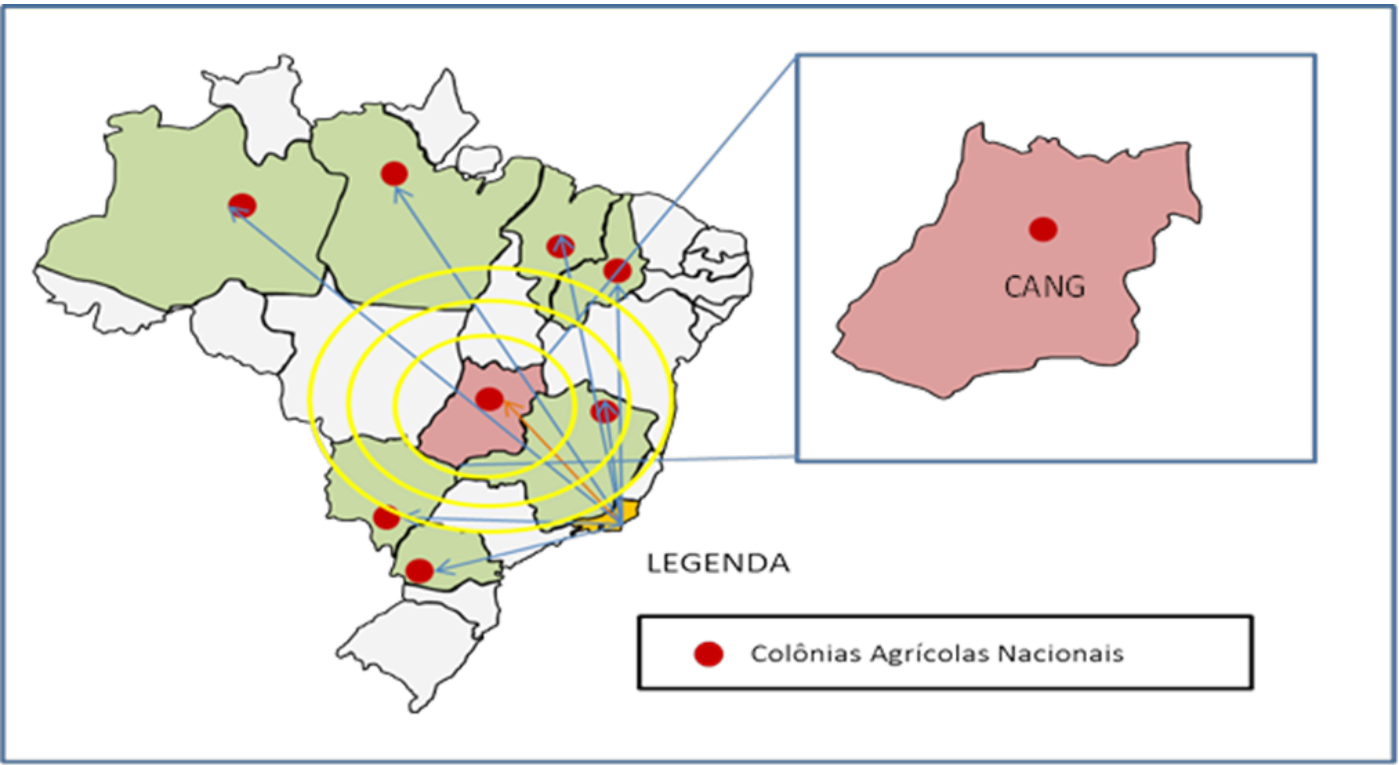

Organizado pelos autores 
Nos pontos demarcados na figura 02 , novos arranjos territoriais foram constituídos. Para integrá-los à Região Concentrada e viabilizar a divisão territorial do trabalho, o Estado fez uso do planejamento como instrumento de política econômica. Para Ianni (1987), esta prática dos governantes é a técnica "mais racional" de organização das informações, dos problemas, das decisões e do controle da execução das intervenções públicas.

Para reforçar o papel do Estado como agente protagonista no processo de ocupação territorial, foi criada, em 1943, a Fundação Brasil Central. Maciel (2011) destaca que a missão da fundação era instalar, no menor tempo possível, rotas de comunicações terrestres, aéreas e de radiocomunicação, entre a cidade do Rio de Janeiro, então Capital Federal, e a cidade de Manaus, situada na região amazônica. Neste contexto, é importante destacar a "Expedição Roncador-Xingu", que é um marco no processo de interiorização e modernização do território.

Promover a materialização de objetos técnicos e articulá-los às demandas nacionais era fundamental para o sucesso das CAN. Da mesma forma, as Colônias sustentariam a expansão dos fixos e fluxos pelo interior do território brasileiro. É o que será abordado no próximo tópico.

\section{AS COLÔNIAS AGRÍCOLAS NACIONAIS E AS DINÂMICAS REGIONAIS}

A Colônia Agrícola Nacional de Goiás (CANG) e a Colônia Agrícola Nacional de Dourados (CAND) se destacaram das demais, pois conseguiram materializar deliberações definidas pelos decretos reguladores das ações da Marcha para o Oeste. O presente artigo ressaltou alguns desdobramentos produzidos no território a partir da primeira Colônia Agrícola implantada: a CANG.

A CANG foi povoada por muitos colonos/ lavradores provenientes de regiões agrícolas tradicionais, que se aventuraram em busca de glebas de terras concedidas pelo governo federal. Martins (2009),

Compreende implicitamente a ideia de que na fronteira se cria o novo, nova sociabilidade, fundada no mercado e na contratualidade das relações sociais. No fundo, portanto, a frente pioneira é mais do que o deslocamento de população sobre territórios novos, mais do que supunham os que empregaram essa concepção no Brasil. A frente pioneira é também a situação espacial e social que convida ou induz à modernização, à formulação de novas concepções de vida, à mudança social. Ela constitui o ambiente oposto ao das regiões antigas, esvaziadas de população, rotineiras, tradicionalistas e mortas. (MARTINS, 2009, p. 135).

Waibel (1958) relata que os colonos pensavam em reproduzir o modelo de agricultura tradicional; ou seja, derrubar e queimar as matas, usar a terra até sua exaustão e, em seguida, migrar para uma nova área. Entretanto, um dos objetivos do processo de colonização implementado pelo Estado era criar mecanismos para fixar o homem na terra e romper com a atividade agrícola migratória. Almejou-se consolidar um modelo de permanência na terra, fazendo com que a rotação de cultura substituísse a rotação de terras.

Segundo Santos e Silveira (2004), este momento constituiu a transição do meio natural para o meio técnico. Nesse sentido, o Cerrado, domínio morfoclimático predominante no Planalto Central, era visto como espaço natural a ser transformado a partir do processo de modernização produtiva. Ele deveria ser artificializado, transformado em paisagem cultural (CORRÊA, 1997, p. 185). Para compreender essa dinâmica, investigou-se o processo de implantação e consolidação da Colônia Agrícola Nacional de Goiás (CANG).

\section{A Colônia Agrícola Nacional de Goiás - CANG}

Ao longo da década de 1940, oito CAN foram instituídas pelo Estado, sendo a CANG a primeira. No Decreto Federal $n^{\circ}$ 6.882, de 19 de fevereiro de 1941, "fica criada a Colônia Agrícola Nacional de Goiás, no Município de Goiás, Estado de Goiás, em terras doadas à União pelo Governo do mesmo Estado, pelo Decreto-Lei Estadual no 3.704 , de 4 de novembro de 1940".

Para definir o local no qual a CANG seria 
instalada, constitui-se uma comissão composta por Oliveira Marques, Eduardo Cláudio, Luiz Honório Ferreira e Luiz Caiado de Godoy; além do Engenheiro Bernardo Sayão, nomeado por Getúlio Vargas para ser o administrador da CANG (SAYÃO, 1984, p. 53). Como destacado anteriormente, os aspectos naturais definiram os locais onde foram instaladas as estruturas físicas da Colônia: a casa do administrador e a sede administrativa.
O Decreto Federal $n^{\circ} 6.882$, em seu parágrafo único, demarca as terras da CANG, estabelecendo como limites: o rio das Almas, o rio São Patrício, o rio Carretão, o divisor de águas dos rios Areias e Ponte Alta, o rio Verde até a confluência com o rio das Almas. A figura 03, elaborada pela Administração da Colônia Agrícola Nacional de Goiás e utilizada por Waibel (1958) em sua pesquisa, apresenta a área da Colônia.

Figura 03: Área da Colônia Agrícola Nacional de Goiás

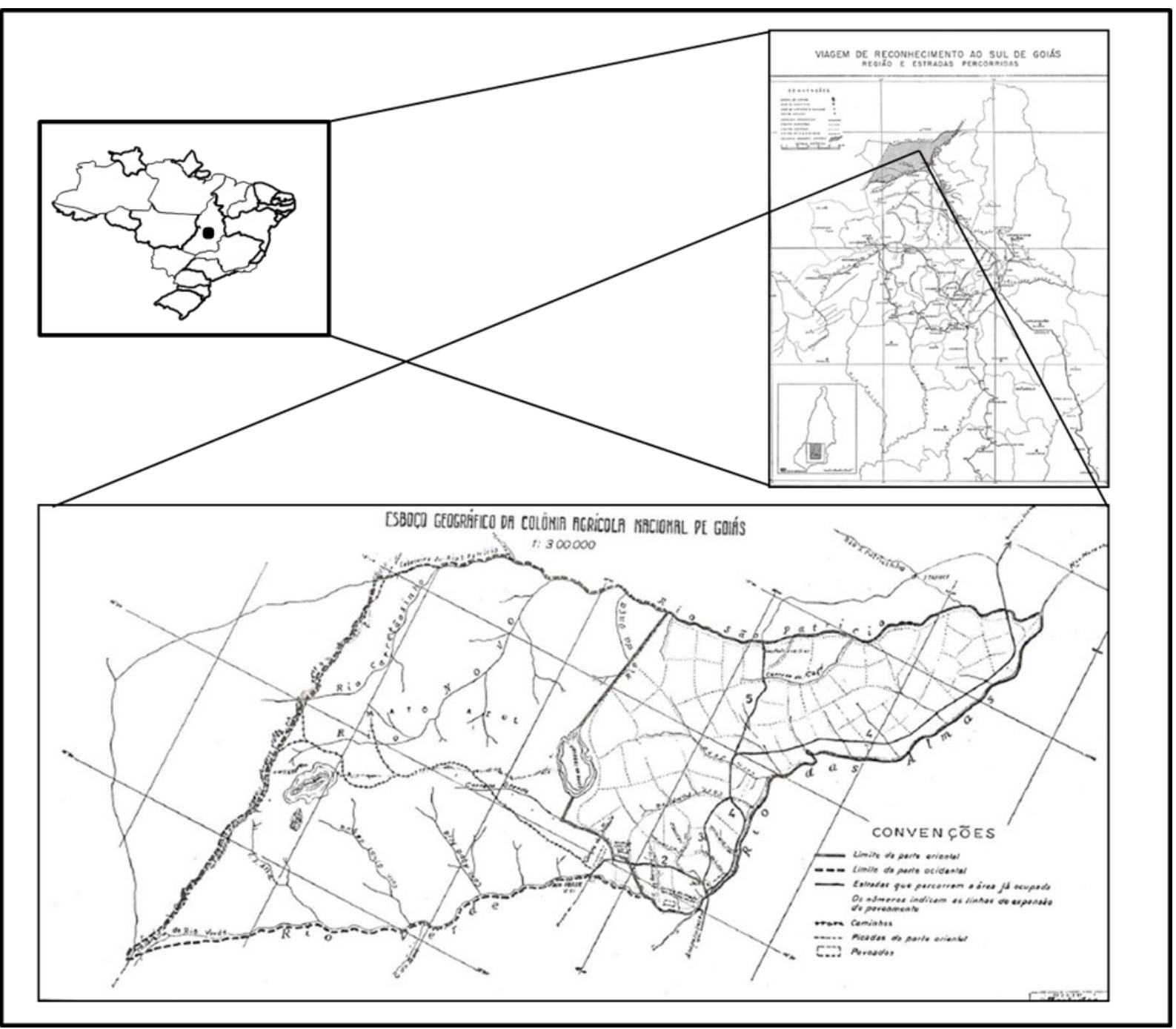

Fonte: Adaptado de Waibel, 1958.

Waibel (1958) esclarece que as glebas localizadas na parte oriental foram ocupadas pelos colonos recém-chegados, pois o acesso era facilitado pela estrada que ligava Anápolis à Colônia. Esta estrada, segundo Faissol (1952), foi concluída em 30 de março de 1944, tornando-se o eixo de escoamento da produção. A ligação estabelecida entre a cidade de Anápolis e a CANG viabilizou a conexão com Colônia Agrícola. Esta conexão abriu os caminhos imprescindíveis para integrar o território "colonizado" à dinâmica capita- 
lista sediada na Região Concentrada.

Segundo Waibel (1958), grande parte dos desbravadores que chegaram à fronteira em expansão - cerca de 60\% - era oriunda de Minas Gerais. Estes colonos faziam uso do trem-de-ferro para chegar até Anápolis. Faissol (1952) ressalta que Anápolis assumiu, no território goiano, a cabeça deste movimento. O geógrafo destaca, ainda, que o Mato Grosso de Goiás compreende

Uma extensa região florestal situada na parte centro-sul do Estado de Goiás. A área de mata original não está ainda calculada precisamente, mas pode-se avalia-la em mais ou menos 20. 000 quilômetro quadrado. Ela começa nas proximidades da cidade de Anápolis e continua para oeste até a base da serra Dourada, na região de Córrego do Ouro; no sentido norte-sul, vai das proximidades de Goiânia até um pouco ao norte de Itapaci. Abrange parte dos municípios de Anápolis, Pirenópolis, Jaraguá, Anicuns, Goiás, Mataúna, Itaberai e Itapaci. Os municipios de Trindade e Inhumas estão inteiramente dentro da mata. (FAISSOL, 1952 p. 7).

Diante da área de abrangência, esta região passou a ser o destino de diversos migrantes que che- gavam de trem e seguiam de caminhão até a CANG. As famílias vindas do norte, oeste e sul do país jornadeavam geralmente a pé, a cavalo ou de caminhão. Ao percorrer este trajeto, Waibel relata que

O estado fisico e higiênico das familias que chegam à colônia era geralmente deplorável: "maltrapilhos, subnutridos e atacados por males endêmicos, dão-nos a impressão da escória de um povo. Para contrabalançar, entretanto, revelam-se-nos otimistas e trabalhadores, sendo muito hospitaleiros e possuindo bom coração". (WAIBEL, 1958, p. 151).

$\mathrm{O}$ art. $13^{\circ}$ do Decreto Federal $n^{\circ} 3.059$, que legitima a criação das CAN, indica uma preocupação com a saúde e prevê assistência médica, farmacêutica e serviços de enfermagem. Como marca tangível desta preocupação ocorreu a construção de um hospital, na CANG, para cuidar das enfermidades dos colonos. Neste contexto, surgiu uma embrionária estrutura médico-hospitalar na sede da Colônia. Segundo Cardoso (2005), o Hospital da Colônia (Figura 04), após o processo de emancipação do município, em 04 de Setembro de 1953, passou a ser administrado pela Igreja Católica/Diocese de Goiás, cujo nome passou a ser "Hospital São Pio X".

Figura 04: Hospital São Pio X

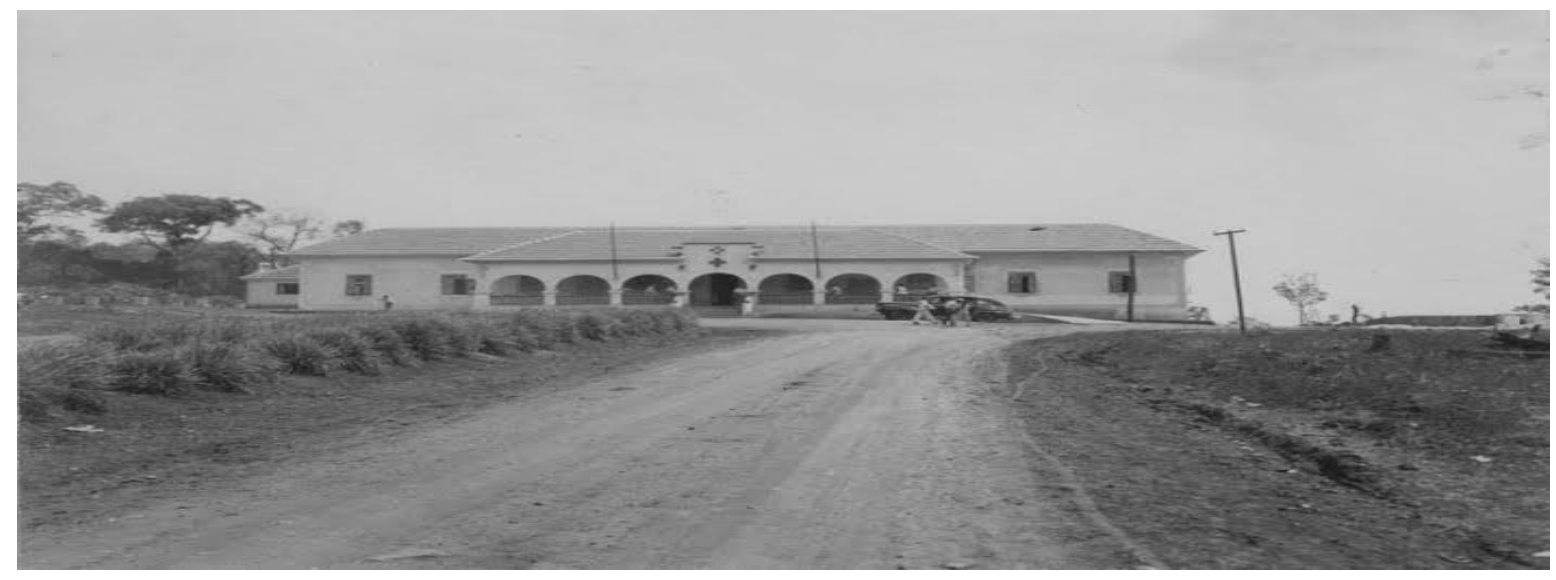

Fonte: Arquivo Público da Câmara Municipal de Ceres (2013). 
Além da saúde, o art. $6^{\circ}$ do decreto citado anteriormente, previa uma estrutura técnica voltada para capacitação dos colonos,

Na sede da colônia será fundado um aprendizado agrícola destinado a ministrar aos filhos dos colonos instrução rural adequada, dotado de oficinas para trabalhos de ferro, madeira, couro, etc., onde os colonos e seus filhos farão aprendizagem desses misteres necessários ao homem rural. (BRASIL, 1941).
Assim, outra questão importante contemplada durante a implantação da CANG foi o ensino formal. $\mathrm{O}$ art. $8^{\circ}$ do Decreto Federal $\mathrm{n}^{\circ} 3.059$, estabelece a criação de escolas primárias para alfabetização de todas as crianças em idade escolar. Segundo Andrade (2006), a professora Helena Andrade Araújo, esposa do pioneiro Dr. Jair Dinoah Araújo, foi convidada, por Bernardo Sayão, para coordenar o setor educacional da Colônia, com vistas à dinamização do processo de aprendizagem escolar. A figura 05 retrata uma unidade escolar que atendia parte da demanda da CANG.

Figura 05: Escola Rural da Colônia Agrícola Nacional de Goiás - CANG

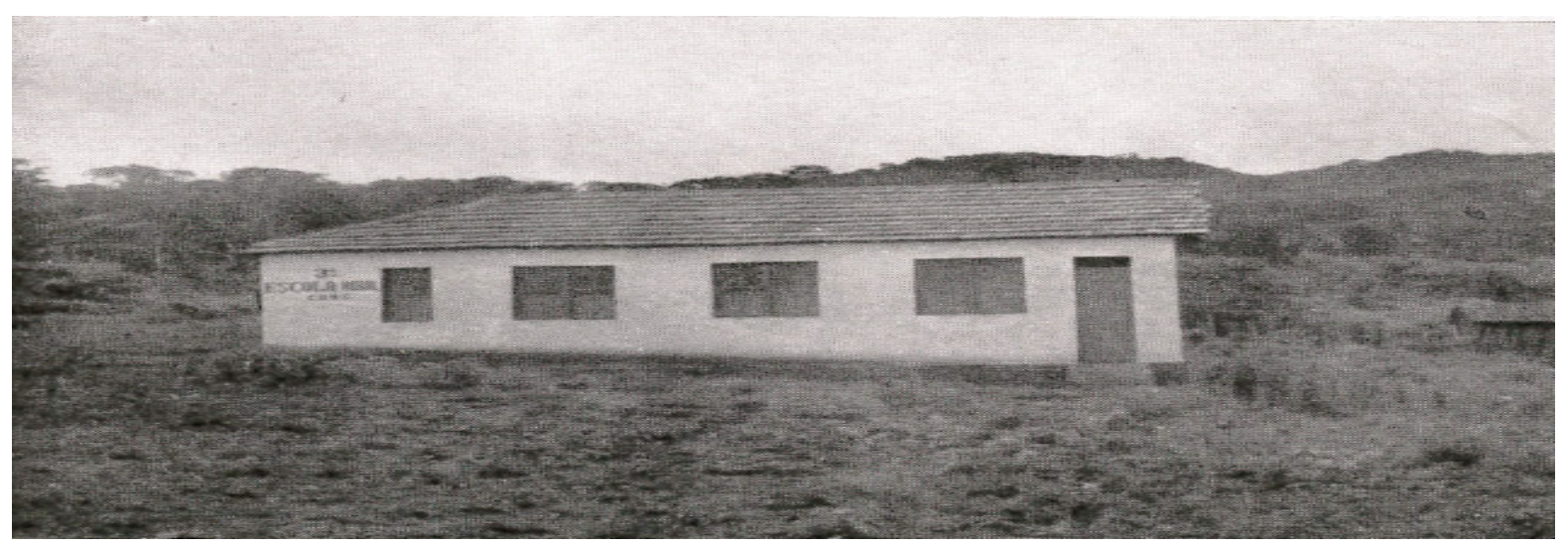

Fonte: Faissol, 1952.

Desta forma, à medida que os recursos federais eram enviados, as diretrizes estabelecidas para as áreas da saúde e educação eram materializadas. Com a construção de uma infraestrutura básica, muitos colonos criaram vínculos e identidade com o lugar recentemente ocupado.
Para Faissol (1952), o objetivo fundamental da CANG era colonizar a área, tornando-a uma região de agricultura moderna em relação aos modelos agrícolas existentes. Os colonos desbravaram a área doada e iniciaram o cultivo de gêneros agrícolas. Dentre os principais destacaram-se os apresentados na tabela 01 ,

Tabela 01: Produção agrícola da CANG

\begin{tabular}{c|l|l}
\hline PRODUTOS & UNIDADES & ANO - 1947 \\
\hline Arroz & Saca de $60 \mathrm{Kg}$ & 220.000 \\
\hline Milho & Saca de $60 \mathrm{Kg}$ & 500.000 \\
\hline Feijão & Saca de $60 \mathrm{Kg}$ & 65.000 \\
\hline Açúcar & Saca de $60 \mathrm{Kg}$ & 5.000 \\
\hline Algodão & Saca de $60 \mathrm{Kg}$ & 10.000 \\
\hline Farinha & Saca de $60 \mathrm{Kg}$ & 35.000 \\
\hline
\end{tabular}

Fonte: Dayrell (1974). 
Parte da produção abastecia o mercado local e o excedente era enviado para um entreposto, em Anápolis, que direcionava os produtos para outros centros urbanos. Os objetos técnicos instalados no território favoreceram a interligação de regiões até então marcadas pelo distanciamento, modificando a Divisão Territorial do Trabalho. Mas um fato deve ser destacado: o fluxo de famílias rumo à CANG exigiu uma disciplina para a ocupação do território. É o que apresentamos a seguir.

\section{Cang: Planejamento e Disciplinarização do Terri- tório}

O planejamento territorial envolve e é envolvido por discursos e práticas de agentes públicos e privados nos processos de agenciamentos de seus interesses. Para Ianni (1987), o planejamento está conectado às questões econômicas, políticas e sociais

Em sintese, as origens da ideologia e da prática do planejamento governamental no Brasil foi uma combinação privilegiada de condições (economia de guerra, perspectivas de desenvolvimento industrial, problemas de defesa nacional, reestruturação do poder político e do Estado, nova constelação de classes sociais) que transformou a linguagem e a técnica do planejamento em um componente dinâmico do sistema político-administrativo. Ou melhor, a linguagem e a técnica do planejamento foram incorporadas de forma desigual e fragmentária, segundo as possibilidades apresentadas pelo sistema político-administrativo e os interesses dominantes do setor privado da economia. (IANNI, 1987, p. 68).

As Colônias Agrícolas apresentam parte do planejamento governamental voltado para a gestão do território nacional no contexto da Segunda Guerra Mundial, quando as relações econômicas internacionais foram alteradas. Nesse período, o Estado brasileiro trabalhava para diversificar a produção industrial e agrícola, com o intuito de atender à demanda interna.

É neste contexto que o Decreto federal $n^{\circ}$
3.059, de 14 de fevereiro de 1941, define a criação das CAN. O decreto oferece elementos para a análise das intenções do Estado, que defendia a busca por um equilibro no uso e na ocupação do território. Para viabilizar o equilíbrio almejado, o processo de colonização emerge através de ações planejadas.

$\mathrm{O}$ art. $5^{\circ}$, do referido decreto, definiu que os projetos das sedes das Colônias deveriam ser pautados em regras urbanísticas que, posteriormente, proporcionariam a criação núcleos civilizatórios no interior do país. Existia uma preocupação quanto ao uso do território e ao planejamento da estrutura física das Colônias. Segundo os relatos de Waibel (1958), ao entrar na Colônia percebia-se, desde o primeiro momento, um planejamento e um controle.

As casas construídas nos lotes concedidos aos colonos eram do tipo mais conveniente à região. Os primeiros colonos receberam materiais para construir suas moradias com estrutura de alvenaria. Contudo, com a intensificação do fluxo migratório e a contenção de recursos, as construções passaram a ser erguidas com tábuas ou mesmo de pau-a-pique (Figura 06). 
Figura 06: Estrutura física de uma moradia construída por uma família de colonos da CANG.

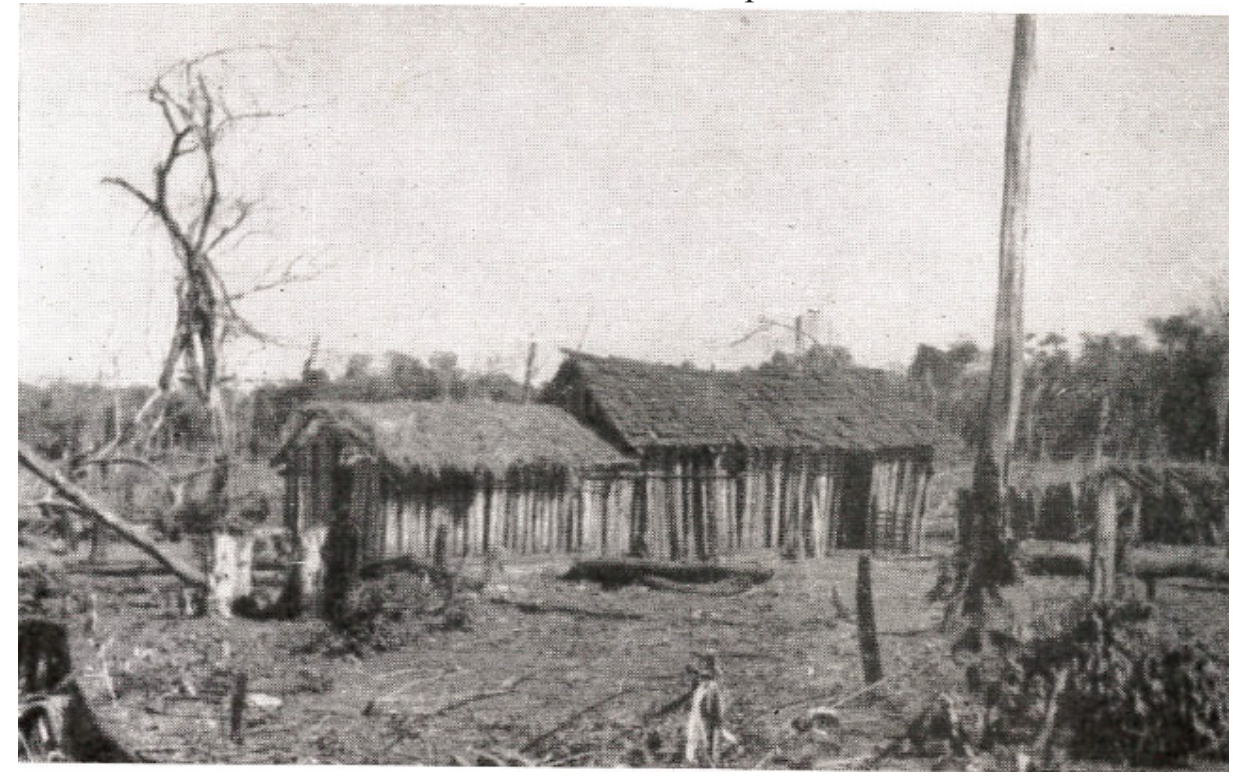

Fonte: Faissol, 1952.

De acordo com os relatos de Faissol (1952), desde a criação da CANG, em 19 de fevereiro de 1941, até o ano de 1944, havia chegado à Colônia cerca de 10 famílias. Com a conclusão da estrada que ligava a Colônia até a cidade de Anápolis, o fluxo foi intensificado e, em julho de 1946, havia na Colônia cerca de 1.600 famílias. Em 1947, eram mais de 2.000 famílias, totalizando mais de 10.000 pessoas. Este contingente populacional mudou, aos poucos, a paisagem regional.

Como cada família trazia consigo uma história de vida carregada de significados, um dos primeiros procedimentos determinados pelo administrador, Bernardo Sayão, era, a partir de requerimentos/ formulários preenchidos pelos interessados, decidir quem tinha perfil para permanecer na Colônia. Muitos não preenchiam os critérios elencados no art. 20 do Decreto Federal $n^{\circ} 3.059$, que determinava

Os lotes rurais serão concedidos a cidadãos brasileiros maiores de 18 anos, que não forem proprietários rurais e reconhecidamente pobres, desde que revelem aptidão para os trabalhos da agricultura e se comprometam a residir no lote que lhes for concedido. (BRASIL, 1941).

Nesse contexto, a alternativa viável para os eliminados no processo de escolha dos colonos era estabelecer residência na margem direita do rio das Almas. O adensamento populacional que se formou à margem direita do rio recebeu o nome de Barranca e, posteriormente, originou o município de Rialma. Os colonos que permaneceram na CANG deveriam seguir as regras contidas no Decreto Federal n ${ }^{\circ} 3.059$. Entre os artigos do decreto que disciplinou o uso do território destacamos o de número 24 . O colono que se enquadrasse em uma das situações abaixo perderia o seu lote:

a) deixar de cultivá-lo dentro dos prazos estabelecidos para cada colônia, salvo motivo de força maior, devidamente comprovado, à juízo da administração da colônia;

b) desvalorizar o lote, explorando matas sem o imediato aproveitamento agrícola do solo e o respectivo reflorestamento, em desacordo com o plano previamente aprovado;

c) por sua má conduta tornar-se elemento de perturbação para a colônia.

O rigor foi utilizado para manter a ordem. Vainer (1989) menciona que o Estado teve que intervir para relocalizar pessoas e reorientar fluxos; enfim, racionalizar a organização espacial e dispor a população ordenadamente no território.

Portanto, o sucesso da colonização exigiu o 
controle de fatores internos (locais) e externos (nacionais). Com relação aos fatores internos: a ordem, a disciplina e o planejamento foram imprescindíveis. Quanto aos fatores externos, os recursos financeiros e as relações políticas e econômicas garantiram os subsídios materiais e imateriais para a consolidação do projeto de colonização. Nesse sentido, a produção do território deveria caminhar em consonância com o discurso do Estado.

\section{CONSIDERAÇÃOES FINAIS}

À medida que o Estado incorporou a prática do planejamento em suas ações e alavancou o processo de modernização, "novos" territórios foram inseridos na Divisão Territorial do Trabalho. Com a inserção de objetos técnicos, o meio natural gradativamente foi transformado em meio-técnico.

A materialização de um projeto nacional por meio das CAN possibilitou uma apropriação embrionária do território rumo ao oeste. Este vanguardismo experimentado por grandes levas de trabalhadores rurais abriu os primeiros caminhos para uma reprodução ampliada do capital, pautada no avanço da dinâmica capitalista nas regiões de fronteira.

O Planalto Central foi inserido, mesmo que de maneira incipiente, em um processo que deveria seguir rumo a Amazônia. A inserção e a fixação de trabalhadores rurais criaram vínculos entre o "O Mato Grosso de Goiás" e centros urbanos de outras Unidades Federativas, rompendo, em parte, com modelos agrícolas tradicionais e implantando, gradativamente, uma agricultura mais tecnificada.

O incremento da produção agrícola voltada ao mercado regional e, em certa medida, ao mercado nacional, proporcionou a implantação de elementos modernizantes (estradas, pontes, núcleos rurais e urbanos). Nesse sentido, os objetos técnicos foram essenciais para territorializar o discurso da Marcha para o Oeste.

Um processo de apropriação do interior do país, especificamente de parte do território goiano, alterou as bases das estruturas produtivas em diferentes escalas. A relação estabelecida entre o governo federal e o governo do estado de Goiás, a partir da criação da CANG (primeira Colônia Agrícola Nacional), propiciou os primeiros traços de práticas agrícolas menos tradicionais, voltadas para demandas que não se limitavam a realidade local.

\section{REFERÊNCIAS}

ANDRADE, N. L. Reforma Agrária: Colônia Agrícola Nacional de Goiás (CANG). 2. ed. Goiânia: Kelps, 2006. p. 144.

AZEVEDO, V. M. R. Marcha para o Oeste: direito à propriedade ou sujeição ao trabalho? Cadernos IPPUR, Rio de Janeiro, v. 3, n. especial, 1989. p. 93-117.

BRASIL. Decreto Lei 2009. Diário Oficial. 9 fevereiro de 1940. Câmara dos Deputados. Disponível em <http://www2.camara.gov.br/legin/fed/declei/1940-1949/decreto-lei-2009-9-fevereiro-1940-411911-publicacaooriginal-1-pe.html> Acesso em 16 de dezembro de 2013.

BRASIL. Decreto Lei 3059. Diário Oficial. 14 fevereiro de 1941. Câmara dos Deputados. Disponível em <http://www2.camara.leg.br/legin/fed/declei/1940-1949/decreto-lei-3059-14-fevereiro-1941-413001-publicacaooriginal-1-pe.html > Acesso em 16 de dezembro de 2013.

BRASIL. Decreto Lei 6882. Diário Oficial. 19 fevereiro de 1941. Câmara dos Deputados. Disponível em <http://www2.camara.leg.br/legin/fed/ decret/1940-1949/decreto-6882-19-fevereiro-1941-333219-publicacaooriginal-1-pe.html> Acesso em 16 de dezembro de 2013.

CARDOSO, F. M. C. Cluster de saúde de CERES (GO): um resgate do seu processo de formação e expansão. Dissertação (Mestrado em Administração). Pontifícia Universidade Católica de Minas Gerais, Belo Horizonte, 2005. 200 p.

CASTILHO, D. A dinâmica socioespacial de Ceres/Rialma no âmbito da modernização de Goiás: território em movimento, paisagens em transição. Dissertação (Mestrado em Geografia), Universidade Federal de Goiás, Goiânia, 2009. 188p. 
CLAVAL, P. Espaço e Poder. Rio de Janeiro: Zahar editores, 1979. p. 248.

COORRÊA, R. L. Trajetórias Geográficas. Rio de Janeiro: Bertrand Brasil, 1997. p. 304.

DAYREL, G. E. Colônia Agrícola Nacional de Goiás: análise de uma política de colonização na expansão para o Oeste. Dissertação (Mestrado em Ciências Humanas e Letras) Faculdade de Educação, UFG, Goiânia. 1974. 163 p.

FAISSOL, S. O "Mato Grosso de Goiás". Rio de Janeiro: IBGE/CNG, 1952. p.140.

IANNI, O. Estado e Planejamento Econômico no Brasil. 4. ed. Rio de Janeiro: Civilização Brasileira, 1987. $316 \mathrm{p}$.

MACIEL, D. P. Estado e território no Centro-Oeste brasileiro (1943-1967). Fundação Brasil Central (FBC): a instituição e inserção regional no contexto sociocultural e econômico nacional. XXVI SIMPÓSIO NACIONAL DE HISTÓRIA-ANPUH, São Paulo, 2011. Anais... São Paulo, 2011. Disponível em: <http://www.snh2011.anpuh.org/site/anaiscomplementares>, Acesso em 27 de Jul./2013.

MARTINS, J.S. Fronteira: a degradação do outro nos confins do humano. São Paulo: Contexto, 2009. 187 p.

MELLO, Marcelo. Brasília e Águas Lindas de Goiás: a loucura e a razão no processo de produção de um território. Tese (Doutorado em Geografia Humana), UFG, Goiânia. 2009.

MONBEIG, P. Pioneiros e fazendeiros de São Paulo. 2. ed. São Paulo: Hucitec/Polis, 1998. 392 p.

REYDON, B. P. A regulação institucional da propriedade da terra no Brasil: uma necessidade urgente. In: RAMOS, P. et. al. Dimensões do agronegócio brasileiro: políticas, instituições e perspectivas. Brasília: MDA, 2007. p. 226-262.

SANTOS, M. A Natureza do Espaço: Técnica e
Tempo, Razão e Emoção. 4. ed. São Paulo: EDUSP, 2006, 260 p.

SANTOS, M. SILVEIRA, M. L. O Brasil: Território e Sociedade no início do século XXI. 6. ed. Rio de Janeiro: Record, 2004. 473 p.

SAYÃO, L. Meu pai, Bernardo Sayão. 4. ed. Brasília: Centro Gráfico do Senado Federal. 1984. p. 512.

VAINER, C. B. Da mobilização para o trabalho à política social - uma reflexão acerca da evolução das políticas de localização da população. Cadernos IPPUR, Rio de Janeiro, ano 3, n.1, p.9-28, 1989.

SILVA, S. D. Os estigmatizados: distinções urbanas às margens do Rio das Almas em Goiás (1949-1059). Tese (Doutorado em História), Universidade de Brasília, 2008. 238p.

WAIBEL, L. Capitulos de Geografia Tropical e do Brasil. Rio de Janeiro: IBGE, 1958. 307 p. 